\title{
Assessment of hemorrhage and paramagnetic substance accumulation in brain metastases by susceptibility weighted imaging
}

\section{Duyarlılık ağ\|rlık\| görüntülleme (SWI) ille beyin metastazlarında hemoraji ve paramanyetik madde birikiminin değerlendirilmesi}

Abdurrahman Göllbaşı, İsmaill Şalk, Nisa Başpınar, Bülent Yıldız

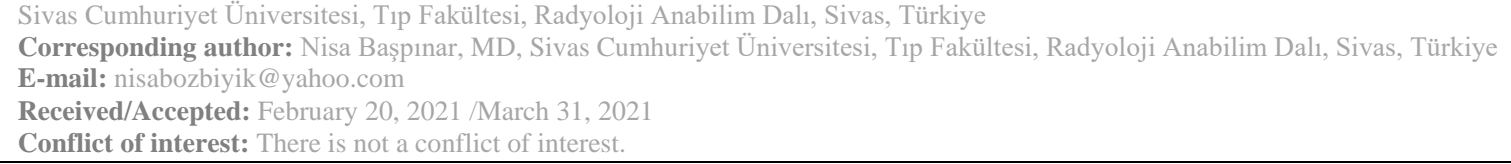

\section{SUMMARY}

Objective: We aimed to make a differential diagnosis of brain metastases by using the percentage of the ITSS by the SWI sequence.

Method: MR images of 77 patients with intracerebral metastases were evaluated in this study who had breast carcinoma $(\mathrm{BC})(\mathrm{n}=23)$, malignant melanoma $(M M)(n=4)$, lung cancer $(\mathrm{LC})(\mathrm{n}=42)$, and gastrointestinal adenocancer (GIA) $(\mathrm{n}=8)$ as the primary tumor. We calculated the ratio of the ITSS pixels.

Results: ITSS percentages of metastases were found $22.52 \%$ in LC, $47.61 \%$ in GIA, $11.85 \%$ in BC, and $60.75 \%$ in MM. In terms of differential diagnosis of the ITSS percentages measured in the SWI sequence, the diagnostic performance was very good between MM-BC, good between MM-LC, GIA-LC, and GIA-BC, and poor between LC-BC and GIA-MM. Percentages of ITSS had high sensitivity and specificity to make a differential diagnosis between GIA-LC, GIA-BC, MM-BC, and MM-LC.

Conclusions: We conclude that measuring the ITSS percentage values of metastases when evaluating brain masses by MRI will provide valuable additional information for differential diagnosis.

Keywords: Brain metastases, susceptibility weighted imaging, MRI
D Abdurrahman Gölbaşı
(D) İsmail Şalk
(iD) Nisa Başpınar
(D) Bülent Yıldız

ORCID IDs of the authors: A.G. 0000-0003-2343-5595 İ.Ş. 0000-0002-5156-6923 N.B. 0000-0003-4240-6001 B.Y. 0000-0003-3836-3184

\section{ÖZET}

Amaç: Beyin metastazlarının değerlendirilmesinde Manyetik Rezonans Görüntüleme (MRG) temel yöntemdir. Son yıllarda duyarlılık ağırlıklı görüntüleme (SWI) adında yeni bir MRG sekansı geliştirilmiștir. SWI sekansında hemoraji ve diğer paramanyetik maddeler duyarlılığa neden olduğu için intratümöral susceptibility signals (ITSS) odakları olarak isimlendirilirler. Çalışmamızda SWI sekansındaki ITSS'leri ölçerek metastazların ayırıcı tanısını yapmayı hedefledik. Yöntem: Çalışmamızda, Ekim 2012 - Ekim 2017 tarihleri arasında Cumhuriyet Üniversitesi Tip Fakültesi Radyoloji Anabilim Dalı'nda beyin MRG'si çekilmiş; akciğer kanseri (AK), gastrointestinal sistem adenokanseri (GİS), malign melanom (MM) ve meme kanseri (MK) tanili 77 hastadan 126 metastaz incelendi. Metastazlar T1A sekansinda belirlenip, SWI sekansında incelendi. SWI sekansında, intratümöral ITSS'li piksel sayısı tüm lezyonun piksel sayısına oranlanıp metastazların ITSS yüzdeleri saptandı.

Bulgular: Metastazlardaki ITSS yüzdeleri, AK'de \%22.52, GíS'te \%47.61, MK'de \%11.85 ve MM'de \%60.75 olarak bulundu. ITSS yüzdesinin tanısal değeri ikili olarak karşılaştırıldığında AK-GíS arasında eğri altında kalan alan 0.734, 
sensitivite 0.61 ve spesifite 0.79 bulundu. Değerler sırasıly AK-MM arası 0.808, 0.75, 0.76, AK-MK arası 0.589, 0.83, 0.40 , GiS-MM arasi $0.634,0.50,0.92$, GiS-MK arasi $0.818,0.83,0.69$ ve MM-MK arasi $0.884,0.95,0.75$ bulundu. Sonuç: SWI sekansında ölçülen ITSS yüzde değerinin ayırıcı tanı açısından etkinliği MM-MK arasında çok iyi, MMAK, GISS-AK ve GIS-MK arasında iyi, AK-MK ve GISS-MM arasında ise yetersiz olarak değerlendirilmiştir. ITSS yüzdesi; MM-MK; MM-AK; GİS-AK ve GİS-MK arasında ayırıcı tanı yapmak için yüksek sensitivite ve spesifite değerleri göstermektedir.

Anahtar sözcükler: Beyin metastazı, SWI, manyetik rezonans görüntüleme

\section{INTRODUCTION}

Brain metastases significantly reduce survival rates in cancer patients. Approximately $10 \%$ of patients with brain metastases are not diagnosed at their admission time to the hospital ${ }^{1}$. Investigation of primary focus, the histopathological diagnosis of metastases, and radiological differential diagnosis are important in determining treatment options for these patients.

Magnetic Resonance Imaging (MRI) is very valuable in evaluating intracranial lesions. However, conventional MRI sequences are insufficient for the evaluation of brain metastases. The Susceptibility Weighted Imaging (SWI) sequence, which has been developed in recent years, has been found valuable for the differential diagnosis of primary brain lesions and metastases ${ }^{2 \text {, }}$ 3,4 .

SWI is a high-resolution 3D spoiled gradient-echo sequence with full flow compensation, filtered phase, and magnitude information. The images that it obtained from the tissues is different from the conventional spin-echo T1A and T2A images. Iron stores such as ferritin and hemosiderin in tissues and iron products in different stages of bleeding are common causes of susceptibility. Because of its superiority in demonstrating blood products, SWI is used to demonstrate intratumoral vascularization, hemorrhage, calcification, and necrosis 5 .

The basis for evaluating the hemorrhagic content of brain lesions with the SWI sequence is based on the detection of intracellular low signal foci called intratumoral sensitivity signals (ITSS).

These foci are usually not observed in conventional MR sequences. ITSS was evaluated qualitatively and quantitatively in some studies ${ }^{2,3}$. Radbruch et al. ${ }^{2}$ reported a method to measure the percentage of ITSS that they called the quantification of percentage (PQ). By this method, they investigated the proportion of the number of pixels of ITSSs in the brain metastases to the total number of pixels in the metastasis. According to the results of this study, they found the mean percentage of ITSS as $1.7 \%$ in breast cancer, $14.3 \%$ in lung cancer, and
$43.7 \%$ in malignant melanoma, respectively. Twenty patients with breast cancer, 15 patients with malignant melanoma, and 49 patients with lung cancer with a total of 84 brain metastases were included in this study. According to the results of the study, mean ITSS in breast, lung, and malignant melanoma cancer metastases were found to be $1.7 \%, 14.3 \%$, and $43.7 \%$ respectively. They reported that the diagnosis and follow-up examinations of the cerebral metastases could be performed successfully using the PQ method with the SWI sequence. In this study, we used the PQ method in the differential diagnosis of metastasis types.

Intratumoral bleeding is frequently seen in brain metastases of thyroid carcinoma, malignant melanoma, choriocarcinoma, and renal cell carcinomas. However, this is also common in lung and breast cancer metastases ${ }^{6}$.

This study aimed to investigate the relationship between the rate of hemorrhage in metastasis and metastatic primary organ tumor by using the SWI sequence.

\section{MATERIAL AND METHODS}

Our study was approved by the local ethics committee, and informed consent was obtained from all the participants.

One hundred and two patients who had MRI images at our hospital's PACS system between October 01, 2012, and October 01, 2017, were found. Patient MRI reports were gathered by using the keyword 'metastasis' for screening. The images of these patients were evaluated retrospectively.

Inclusion criteria;

- Patients with at least $1 \mathrm{~cm}$ diameter and at least 1 brain metastasis,

- Patients who have both histopathological and radiological diagnoses are determined from patient files in our hospital.

Exclusion criteria;

- Patients who do not have brain MRI examination before biopsy or radiotherapy in our hospital 
- Patients who have been previously operated or treated

Seventy-seven patients who fulfilled the inclusion criteria were included.

\section{MR-imaging protocol}

All patient's images were acquired using a $1.5 \mathrm{~T}$ MRI unit (Magnetom Aera, Siemens, Erlangen, Germany) with a 20-channel phased-array head coil. Our conventional MR imaging protocol included the following sequences: pre- and postcontrast axial and coronal T1-weighted fast spinecho (FSE) images (520 ms repetition time [TR], $5.6 \mathrm{~ms}$ echo time [TE], $150^{\circ}$ flip angle [FA], 3 averages, $220 \times 84$ field of view [FOV], $256 \times 100$ matrix, $5 \mathrm{~mm}$ section thickness, $1.7 \mathrm{~mm}$ intersection gap). Axial, coronal, and sagittal T2weighted FSE images (4350 ms TR, $102 \mathrm{~ms}$ TE, $150^{\circ} \mathrm{FA}, 2$ averages, $220 \times 97 \mathrm{FOV}, 320 \times 90$ matrix, $5 \mathrm{~mm}$ section thickness, $1.7 \mathrm{~mm}$ intersection gap), and axial and sagittal fluid-attenuated inversion recovery (FLAIR) images (9000 TR, $84 \mathrm{~ms}$ TE, $2500 \mathrm{~ms} \mathrm{TI}, 150^{\circ} \mathrm{FA}, 1$ average, $220 \times 84 \mathrm{~mm}$ FOV; $320 \times 90$ matrix; $5 \mathrm{~mm}$ section thickness, $1.7 \mathrm{~mm}$ intersection gap) were obtained. SWI parameters were $49 \mathrm{~ms}$ TR, $40 \mathrm{~ms}$ TE, 2 averages, $288 \times 90 \mathrm{~mm}$ FOV, $288 \times 90$ matrix, $0.8 \times 0.8 \times 4 \mathrm{~mm}$ voxel size, $15^{\circ} \mathrm{FA}, 5$ minutes 55 seconds acquisition time. An intravenous paramagnetic contrast agent (0.1 $\mathrm{mmol} / \mathrm{kg}$ gadolinium-DTPA or gadodiamide) was administered to all patients.

\section{Image Analysis}

Images were evaluated on a free-access software called, "Medical Image Processing and Visualization" (MIPAV), (The software can be reached from the address https://mipav.cit.nih.gov The current access date is August 21, 2020). Contrast-enhanced T1-weighted images and SWI images were registered. T1A images were subjected to the "automatic optimized registration" process and the slice numbers of the T1A images were equalized with the SWI image. This process ensured that the lesion on T1A is in the same slice and the same localization on SWI. On contrastenhanced T1W images, all enhancing lesion's contour was drawn, and the region of interest (ROI) of lesions was created and the created ROI's were transferred to the corresponding SWI images (Figure 1). The second region of interest created in the lateral ventricles on the SWI images was also determined. After determining the average signal intensity of cerebrospinal fluid, below average signal intensity-susceptibilities pixels (SP) and the total number of pixels (TP) concerning the lesion were calculated. Subsequently, the ratio of the SP to TP was calculated and ITSS percentages were found.
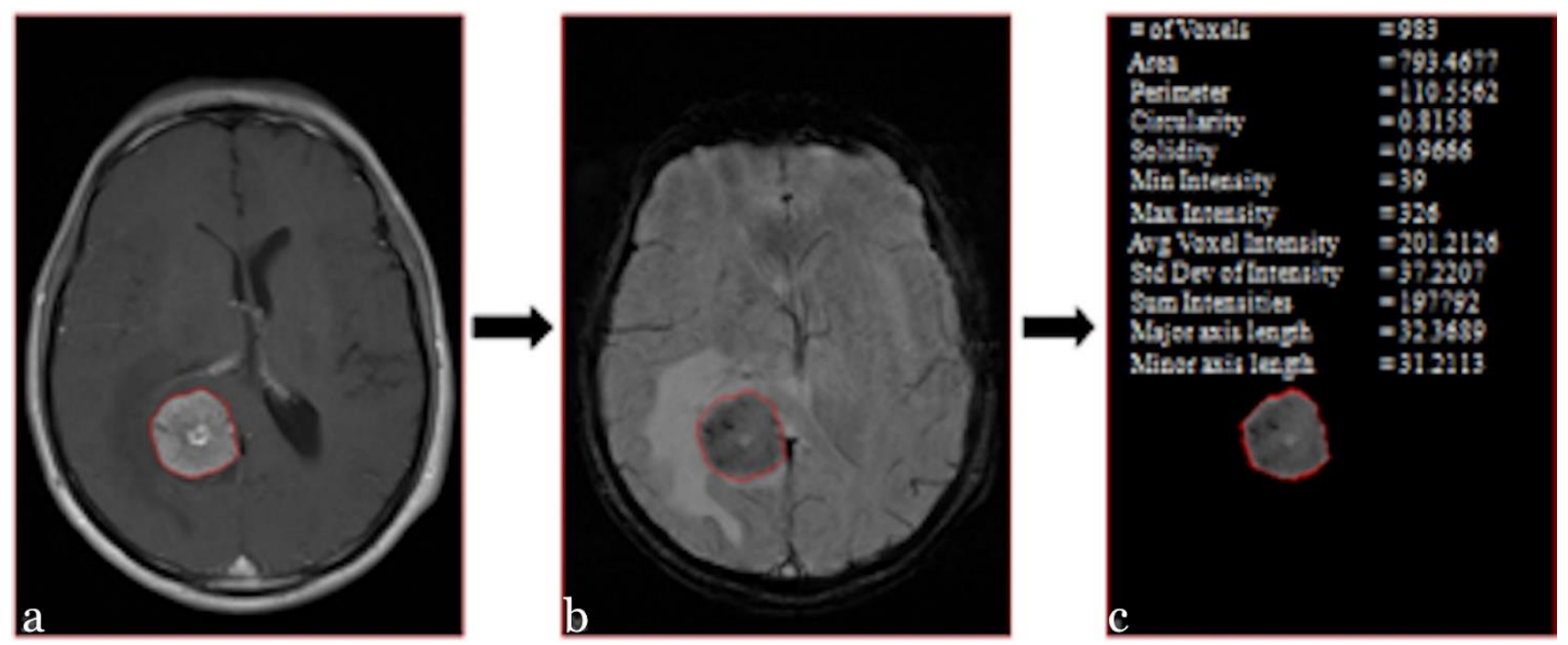

Figure 1: ROI created in contrast enhanced T1A and SWI image.

\section{Statistical analysis}

Chi-square value was calculated by using the ChiSquare exact test (with Monte Carlo method), and the error level was taken as 0.05 . ROC-analysis was performed for the differentiation of MM vs. $\mathrm{MC}, \mathrm{MM}$ vs. $\mathrm{BC}$, and $\mathrm{BC}$ vs. MC using SPSS
Software (ver:22.0). Sensitivity and specificity were calculated according to ROC-analysis.

\section{RESULTS}

Of the evaluated 77 patients, a total of 126 intracerebral metastasis were identified $(68$ 
metastases from 42 patients of LC, 41 metastases from 23 patients of $\mathrm{BC}, 13$ metastases from 8 patients of GIA, and 4 metastases from 4 patients of MM). The demographic characteristics of the patients are shown in Table 1.

Table 1. Demographic characteristics of patients with lung carcinoma (LC), breast carcinoma (BC), gastrointestinal adenocarcinoma (GIA), and malignant melanoma (MM).

\begin{tabular}{|l|l|l|l|l|}
\hline & LC & BC & GIA & MM \\
\hline Female & & & & \\
Male & 6 & 23 & 1 & 1 \\
\hline Age, mean \pm SD & 36 & 0 & 7 & 3 \\
\hline Metastasis, n & $61 \pm 8.8$ & $47.4 \pm 8.3$ & $60.8 \pm 6.2$ & $43.5 \pm 18$ \\
\hline LC; lung carcinoma, BC; breast carcinoma, GIA; gastrointestinal adenocarcinoma, MM; \\
malign melanoma
\end{tabular}

Mean ITSS percentages in metastases were found to be $11.85 \%$ in BC, $22.52 \%$ in $\mathrm{LC}, 47.61 \%$ in GIA, and $60.75 \%$ in MM. In 14 patients ITSS percentages were calculated as $0 \%$ in whom 8 of them were BC and 6 of them were LC. And two of four MM metastases had over 90\% ITSS percentage. An ITSS percentage above $40 \%$ was not observed in BC metastases. There was a significant difference between ITSS percentages of metastasis types $(\mathrm{p}<0.05)$. Mean ITSS percentages of $\mathrm{LC}$ and $\mathrm{BC}$ were found to be lower than the ones in GIA and MM cancers. ITSS percentages of metastasis were shown in Figure 2.

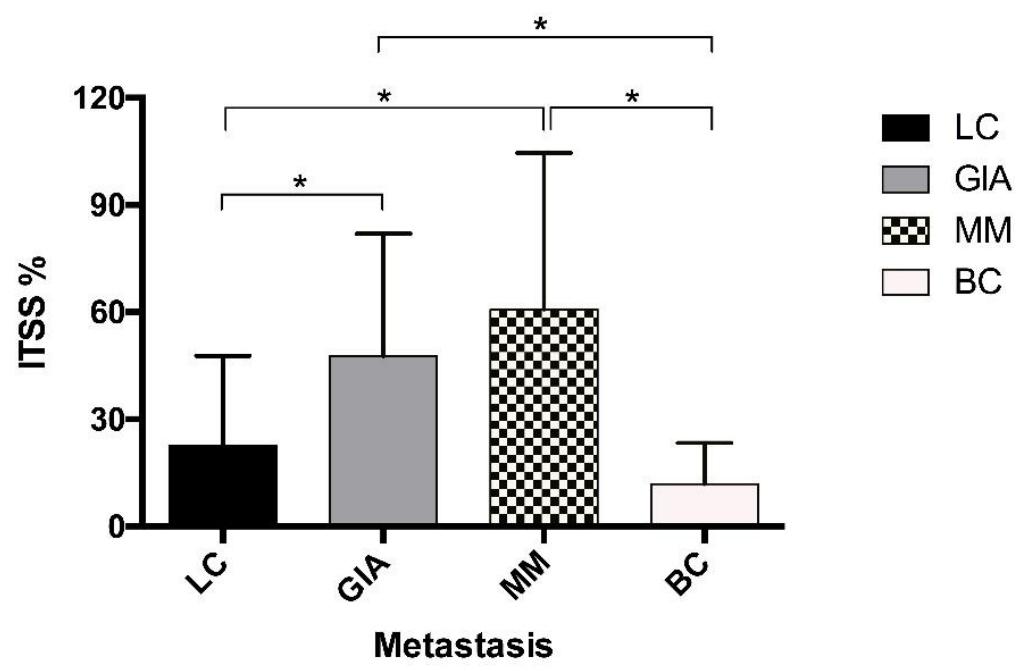

Figure 2: ITSS percentages of metastasis (LC; lung carcinoma, BC; breast carcinoma, GIA; gastrointestinal adenocarcinoma, MM; malign melanoma). 
Diagnostic values of ITSS percentages were compared between tumor types. The threshold values and area under curves (AUC) were found to be $41(\mathrm{AUC}=0.734)$ between LC and GIA, 36 (AUC $=0.808$ ) between LC and MM, 21 (AUC $=0.589$ ) between LC and BC, 91 (AUC $=0.634$ ) between GIA and MM, 22 (AUC $=0.818$ ) between GIA and BC, 37 (AUC $=0.884$ ) between MM and $\mathrm{BC}$ respectively.

According to the results of the ROC curve analysis, the efficiency of the ITSS percentage in differential diagnosis was found to be very good between MMBC, good between MM-LC, GIA-LC, and GIA$\mathrm{BC}$, and insufficient between LC-BC and GIA-
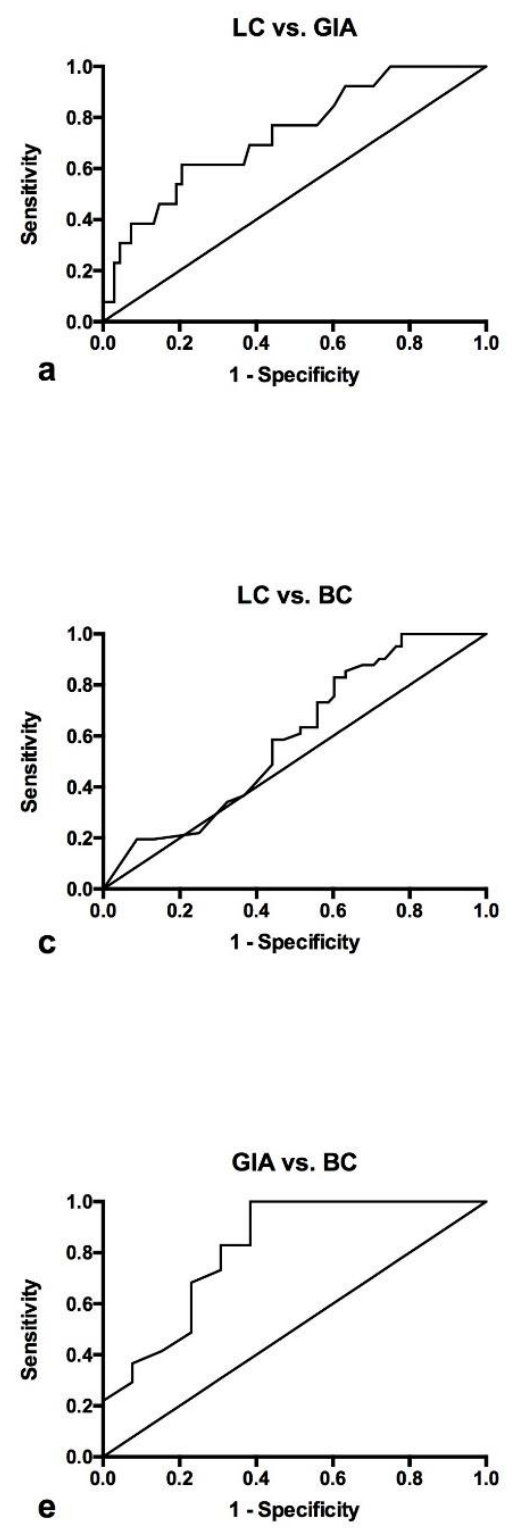

MM. ROC analysis results performed between various tumor types are shown in Figure 3 a-f.

The relationship between tumor size and ITSS percentage was evaluated. No positive or negative correlation was found between the increased tumor size and ITSS percentage $(r=0.101, p>0.05)$. Correlations between tumor sizes and ITSS percentages were shown in Figure 4.

Metastasis types were evaluated according to the number of metastases. Metastases were mostly three or more. Solitary brain metastasis was not observed in $23 \%$ of the patients $(n=21)$. The distribution of metastasis types according to the number of metastases was shown in Figure 5.
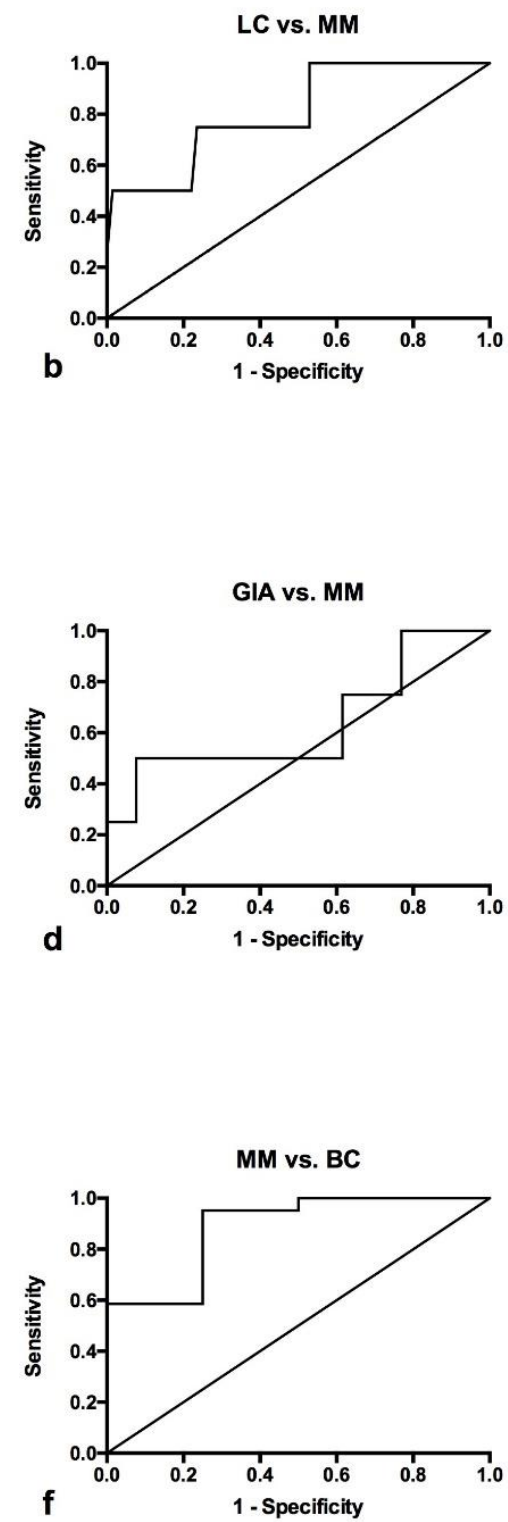

Figure 3: ROC analysis between tumor types, a; LC vs GIA, b; LC vs MM, c; LC vs BC, d; GIA vs MM, e; GIA vs BC, f; MM vs BC (LC; lung carcinoma, BC; breast carcinoma, GIA; gastrointestinal adenocarcinoma, MM; malign melanoma). 


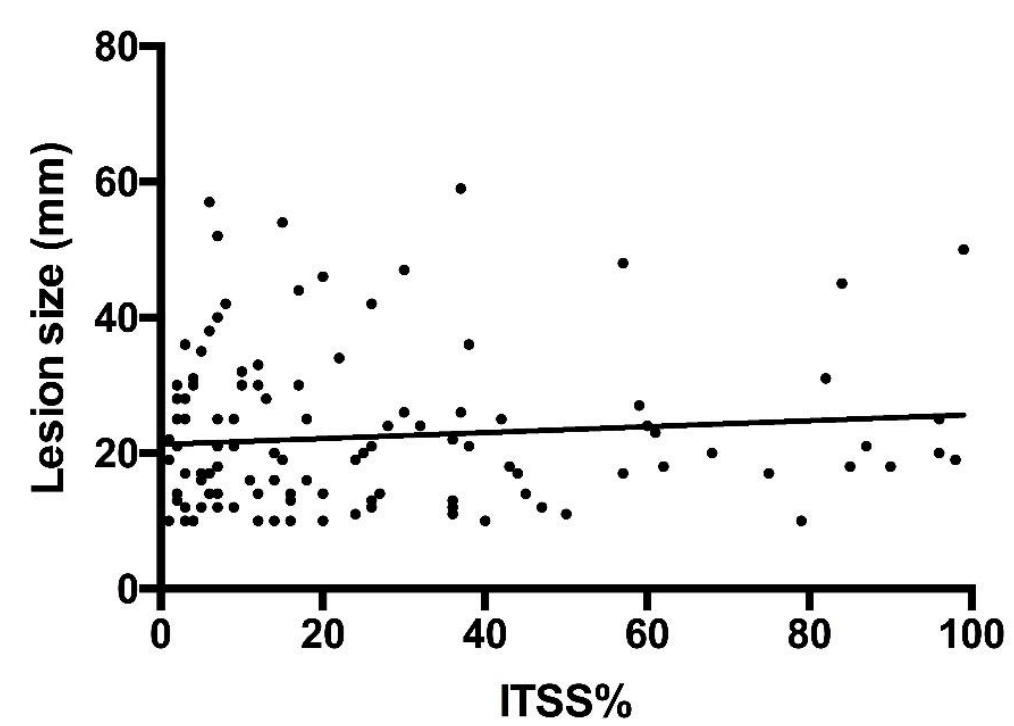

Figure 4: Correlation between tumor sizes and ITSS percentages (ITSS: Intratumoral susceptibility signal).

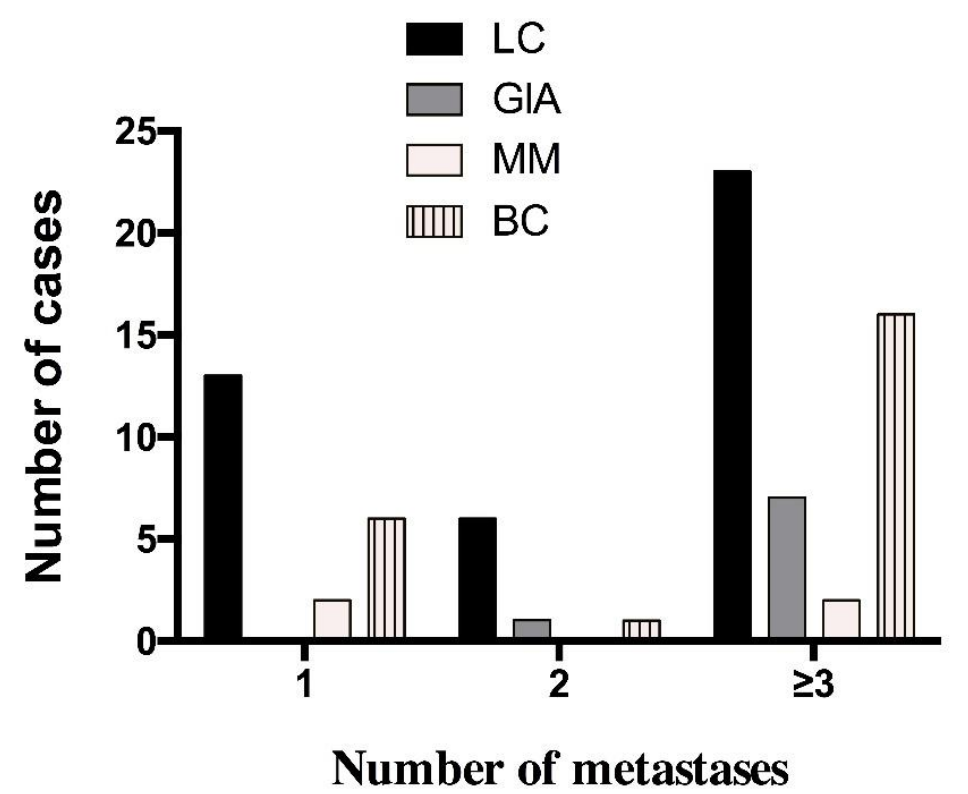

Figure 5: Distribution of metastasis types according to the number of metastases (LC; lung carcinoma, BC; breast carcinoma, GIA; gastrointestinal adenocarcinoma, MM; malign melanoma).

Metastasis types were evaluated according to the metastatic localization in the brain. The metastases were multifocal and frequently present in the frontal lobe. Distribution of the localizations of metastatic brain tumors was shown in Figure 6. 

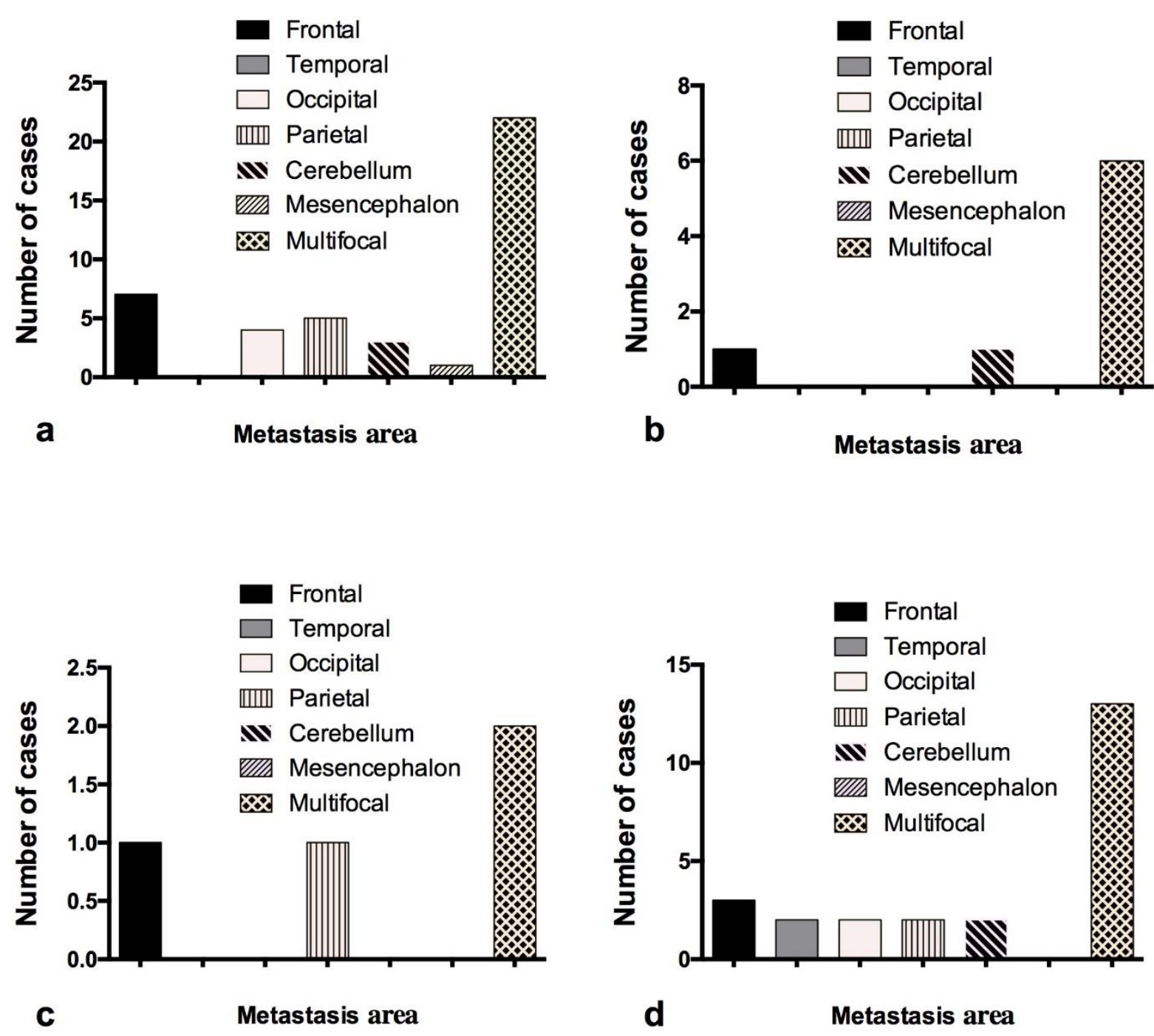

Figure 6: Distribution of the localizations of metastatic brain tumors.

\section{DISCUSSION}

In our study, we aimed to make a differential diagnosis of brain metastases with the SWI sequence, which is a relatively new sequence. We tried to reach objective values by comparing the sensitivity foci in the SWI sequence to the whole tumor mean. ITSS percentage values were found to be $11.85 \%$ in BC, $22.52 \%$ in LC, $47.61 \%$ in GIA, and $60.75 \%$ in MM. While high ITSS percentage was observed in MM metastases and low ITSS percentage was observed in BC metastases, medium-high values were suggestive of GIA metastasis and low-medium values were suggestive of LC metastasis. According to the results of our study, it was found that the differential diagnosis of LC, BC, GIA, and MM metastases can be made by the percentage of ITSS.
In high ITSS values, LC and BC metastasis can be ruled out to a great extent, whereas in low values GIA and MM metastasis can be excluded. When we look at hemorrhage rates of metastases, it is consistent with the literature that MM metastases have shown very high ITSS values ${ }^{2,7}$ This effect is thought to be due to the paramagnetic property of melanin, and the high tendency of hemorrhage in MM metastases ${ }^{8,9}$. In contrast to MM metastases, studies are reporting that $\mathrm{BC}$ metastases show low ITSS values ${ }^{2,4}$. There are few studies in the literature showing the SWI sequence is effective in the differential diagnosis of brain masses. In the differential diagnosis of brain metastases among themselves and primary central nervous system tumors, there are also very few studies on the efficiency of the SWI sequence. 
Radbruch et al. ${ }^{2}$ evaluated a total of 167 brain metastases of $49 \mathrm{LC}, 20 \mathrm{BC}$, and $15 \mathrm{MM}$ in their study. In their study, the mean ITSS value was found to be $1.7 \%$ in BC metastases, $14.3 \%$ in LC metastases, and $43.7 \%$ in MM metastases. The mean ITSS values we found in our study were very similar to those in Radbruch et al. ${ }^{2}$. Radbruch et al. ${ }^{2}$ determined the predictive value between MM and $\mathrm{BC}$ to be $3 \%$, and they stated that this value provides a distinction between these two tumor metastases with a sensitivity of 0.85 and a specificity of 0.93 . These values were $20,0.67$, and 0.84 between LC and BC, and 3, 0.85, and 0.47 between $\mathrm{LC}$ and $\mathrm{BC}$, respectively. They reported that the diagnostic efficacy was excellent in the differentiation between LC and BC, that it was good for MM and LC, and that it was poor in the difference between BC and LC. In terms of diagnostic efficacy, in this study, we can describe it as very good between MM and BC, good between MM and LC, and weak between LC and $\mathrm{BC}$. The diagnostic performance values of both studies show a great similarity regarding $\mathrm{LC}, \mathrm{BC}$, and $\mathrm{MM}$ distinction. In our study, GIA was added in addition to $\mathrm{LC}, \mathrm{BC}$, and $\mathrm{MM}$.

Kim et al. ${ }^{3}$ retrospectively reviewed 64 patients with solitary contrast-enhanced lesions in the brain to evaluate the contribution of the SWI sequence to the diagnosis. Pathological diagnosis of the patients consisted of 6 categories: Glioblastoma multiforme (GBM), anaplastic astrocytoma, metastasis, lymphoma, tumefactive multiple sclerosis (MS), and inflammatory granuloma. They divided the study into two stages which they called qualitative and semi-quantitative. They evaluated the contribution of the SWI sequence in the qualitative stage for diagnosis. While 43 (67\%) of 64 patients were diagnosed correctly with conventional MRI sequences, they made the correct diagnosis in $50(78 \%)$ patients by adding SWI to the sequences. In the semi-quantitative stage, they categorized the ITSS to grade 1, 2, 3 to evaluate the contribution of the SWI sequence to the differential diagnosis. They reported that ITSS showed very high sensitivity and sensitivity in differentiating lymphoma from high-grade gliomas (GBM and anaplastic astrocytoma) and nontumoral (MS and granuloma). They also found that they did not have sufficient sensitivity and sensitivity values to make a differential diagnosis between metastasis and GBM with ITSS value.

Kim et al.'s ${ }^{3}$ study included four patients with ITSS grade 1, five patients with grade 2 , and six patients with grade 3 . We did not perform an ITSS grading in our study. In our study, the percentage of ITSS was measured, and we found the value between 0-99. In both studies by Kim et al. ${ }^{3}$ and us, it was seen that the ITSS values of metastases were distributed over a wide range. However, in our study, the ITSS percentage of metastases showed significant differences within themselves. We think that successful results will be obtained when it is desired to differentiate MM with very high ITSS values and BC with very low values from GBM showing very high values together with lymphoma and other non-tumoral lesions that show almost no ITSS by the percentage of ITSS. There is a need for research on this subject.

Francheschi et al. ${ }^{4}$ in their study, determined the prevalence of hemorrhage of $\mathrm{MM}$ and $\mathrm{BC}$ brain metastases using the SWI sequence. They evaluated 467 brain metastases in $38 \mathrm{BC}$ patients and 485 brain metastases in $35 \mathrm{MM}$ patients. Metastases smaller than $0.1 \mathrm{~cm}^{3}$ were categorized as micrometastases and larger than $0.1 \mathrm{~cm}^{3}$ were categorized as macrometastases. According to the presence or absence of ITSS in metastases, they classified SWI as positive or negative. According to the results of the study, 342 of the metastases were categorized as micrometastasis and 610 of them were macrometastasis. Ten of the micrometastases and 410 of the macrometastases were SWI positive. $76.9 \%$ of MM and $55.6 \%$ of BC were SWI positive regardless of tumor volume. Furthermore, when lesions over $1.5 \mathrm{~cm}^{3}$ were evaluated, all eight MM metastasis was evaluated as SWI positive and only one of $15 \mathrm{BC}$ metastases were SWI positive. It was concluded from the study that intratumoral hemorrhage in brain metastases is not a common condition in micrometastases but is common in macrometastases. They also reported that MM brain metastases showed more SWI positivity than $\mathrm{BC}$ brain metastases and became more pronounced as tumor size increased in their study.

We measured SWI values quantitatively with the help of the program in this study. In our study, the $0 \%$ ITSS patients, and the patients described by Francheschi et al. ${ }^{4}$ as SWI negatively expressed the same situation. In the study by Francheschi et al. ${ }^{4}$, while $44.4 \%$ of patients with BC were SWI negative, $20 \%$ of our patients had $0 \%$ ITSS. In our study, the relationship between tumor size and the amount of bleeding was also examined. There was no correlation between the amounts of bleeding and tumor size. Francheschi et al. ${ }^{4}$ reported a positive correlation between the frequency of bleeding and tumor size. The incidence of bleeding was not evaluated in our study.

The SWI sequence shows small venous structures precisely due to the paramagnetic effect of 
deoxyhemoglobin ${ }^{10}$. There are studies in which differential diagnosis of brain masses are made by evaluating these small venous structures ${ }^{11}$ and grading astrocytoma's ${ }^{12}$.

Ding et al. ${ }^{11}$ evaluated primary central nervous system lymphoma (PSSL), high-grade glioma, and brain metastases with the SWI sequence. In their study, they separated the microvascular structures from hemorrhage with the help of MIP images and examined the results in two, different categories as intralesional hemorrhage and vascularization. In the results of the study, sensitivity and specificity values were found to be sufficient to differentiate between PSSL and high-grade glioma and metastasis. They reported that the results were not statistically significant when high-grade gliomas and metastases were compared for differentiation. When intralesional bleeding and vascularity were compared, they reported that intralesional vascularization had higher sensitivity and specificity values between PSSL and non-PSSL.

Li et al. ${ }^{12}$, evaluated nine low-grade, 13 high-grade astrocytoma cases in their study. They reported significant differences between the number of small vessels and the degree of astrocytoma. In studies comparing metastases with other brain masses using the SWI sequence, we can say that the differential diagnosis of metastases with lymphoma and non-tumoral lesions is generally successful. However, in our study, we predict that BC with low-level ITSS will be difficult in differential diagnosis with lymphoma and nontumoral lesions which may also present with very low-level ITSS.

There are some limitations to our study. One limitation of our study was that we did study the percentage of ITSS but not the distribution and morphology of intra-tumor ITSS. We believe that factors such as central/peripheral localization, focal/general, and linear/circular ITSS may contribute to the diagnosis. One of the limitations of our study was our MRI device had 1.5 Tesla field strength. Because with 3.0 Tesla field power devices, the SWI sequence offers high spatial resolution, with much shorter shooting times and better signal-to-noise ratios (SNRs).

\section{CONCLUSION}

In our study, we believe that MM and GIA with very high ITSS may have difficulty in differential diagnosis with GBMs with very high ITSS. Despite these difficulties, we think that knowing the ITSS percentage values of metastases when evaluating brain masses by MRI will provide valuable additional information for differential diagnosis. Larger studies are needed to investigate the ITSS characteristics of metastases, and primary brain tumors in the SWI sequence.

\section{REFERENCES}

1. Khan RBDL. Brain metastases. In: Schiff DWP, editor. Cancer neurology in clinical practice. Totawa, NJ, USA: Humana Press; 2003

2. Radbruch A, Graf M, Kramp L, Wiestler B, Floca R, Bäumer $\mathrm{P}$, et al. Differentiation of brain metastases by percentagewise quantification of intratumoral susceptibility signals at 3Tesla. Eur J Radiol. 2012 Dec; 81(12):4064-8. [PubMed: 22795527]

3. Kim HS, Jahng GH, Ryu CW, Kim SY. Added value and diagnostic performance of intratumoral susceptibility signals in the differential diagnosis of solitary enhancing brain lesions: preliminary study. AJNR Am J Neuroradiol. 2009;30:1574-9

4. Franceschi AM, Moschos SJ, Anders CK, Glaubiger S, Collichio FA, Lee CB et al. Utility of Susceptibility Weighted Imaging (SWI) in the Detection of Brain Hemorrhagic Metastases from Breast Cancer and Melanoma. Journal of computer assisted tomography. 2016;40(5):803-805. doi:10.1097/RCT.0000000000000420.

5. Mohammed W, Xunning H, Haibin S, Jingzhi M. Clinical applications of susceptibilityweighted imaging in detecting and grading intracranial gliomas: a review. Cancer Imaging. 2013;13:186-195

6. Fischbein NJ, Wijman CA. Nontraumatic intracranial hemorrhage. Neuroimaging Clin $\mathrm{N}$ Am. 2010 Nov; 20(4):469-92. [PubMed: 20974372]

7. Gaviani P, Mullins ME, Braga TA, HedleyWhyte ET, Halpern EF, Schaefer PS, et al. Improved detection of metastatic melanoma by $\mathrm{T} 2 *$-weighted imaging. American Journal of Neuroradiology 2006;27(3):605-8

8. Mandybur TI. Intracranial hemorrhage caused by metastatic tumors. Neurology 1977;27(7):650-5.

9. Isiklar I, Leeds NE, Fuller GN, Kumar AJ. Intracranial metastatic melanoma: correlation between MR imaging characteristics and melanin content. American Journal of Roentgenology 1995;165(6):1503-12.

10.Rauscher, A., Sedlacik, J., Barth, M. et al. Noninvasive assessment of vascular architecture and function during modulated blood oxygenation using susceptibility 
weighted magnetic resonance imaging. Magn Reson Med. 2005; 54: 87-95

11.Ding Y, Xing Z, Liu B, Lin X, Cao D. Differentiation of primary central nervous system lymphoma from high-grade glioma and brain metastases using susceptibility-weighted imaging. Brain and Behavior. 2014;4(6):841849. doi:10.1002/brb3.288.

12.Li C, Ai B, Li Y, Qi H, Wu L. Susceptibilityweighted imaging in grading brain astrocytomas. Eur J Radiol. 2010;75:e81-5. 